\title{
Surrogate mothering in White Leghorn chicks
}

\author{
NORMA C. REESE \\ University of Southern Mississippi, Hattiesburg, Mississippi 99401
}

\begin{abstract}
The present study investigated the effectiveness of two types of surrogates in reducing isolation-related death rates occurring between the 4th and 7th days after hatching in chicks. A red tennis ball suspended from the cage ceiling was as effective as group rearing in maintaining a low death rate ( $25 \%$ and $12 \%$, respectively). A flashing light was ineffective in reducing death rate compared to rearing in isolation $(72 \%$ and $75 \%$, respectively). This supports Harlow's work with infant monkeys on the importance of tactile stimulation and extends it to a lower species than had been previously considered. The flashing light was probably ineffective because the chicks were unable to achieve physical contact with the light. It was not determined that all chicks received enough food to survive. It is likely that the chick's need for stimulation in the form of a touchable imprinting object is prepotent over its hunger drive. Although all chicks were observed eating, some may have spent energy and time seeking contact with an imprinting object that was impossible to attain, thus failing to engage in sufficient eating behavior.
\end{abstract}

The present study compared the effects of total isolation with two types of surrogate mothering in chicks. Prolonged exposure to a monotonous environment has profound effects in humans (Heron, 1957). Sensory deprivation has produced the effects of impaired thinking, childish emotional response, perceptual distortion, hallucinations, and alterations in brain wave patterns. Harlow's (Harlow \& Griffin, 1965) numerous studies of infant love in monkeys suggest that: (1) Isolation for long periods of time during infancy results in severe emotional maladjustment in adult monkeys, and (2) tactile stimulation from artificial cloth mothers can alleviate the profound effects of isolation on monkeys, In chimps, total isolation for 12 months resulted in severe irreversible pathological behavior.

In this laboratory, attempts to totally isolate chicks during the imprinting period have resulted in high death rates occurring between the 4th and 7 th days after hatching. Others have found that early isolation results in retarded social development (Ratner, 1965) and in a shortened duration of the tonic immobility response in chicks (Reese, 1976; Salzen, 1963). Osamu and Masataka (1971) found dark-reared chicks to be less fearful on an open-field test. These findings have been replicated in this laboratory with White Leghorn and Cob \& Cob chickens which survived isolation procedures.

Isolation is a term that is not consistently used in the literature. In Ratner's (1965) study, isolation occurred $24 \mathrm{~h}$ after hatching. In the Osamu and Masataka (1971) study, chicks were isolated for only 3 days. Age of isolation and amount of outside stimulation, such as ex-

Requests for reprints should be sent to Norma C. Reese, Department of Psychology, University of Southern Mississippi, Box 1174 Southern Station, Hattiesburg, Mississippi 39401. J.C. Koeppel sponsors and takes full responsibility for this paper. posure to humans, varies considerably in the literature on isolation in chickens. No studies were found which attempted to control auditory stimulation, nor did this one.

Chicks placed into isolation for more than 3 days are deprived of an effective imprinting object during the critical period (Hess, 1958). The object need not be live and may even be a rotating light (Bateson \& Reese, 1968). Since the death rate imposed by total isolation presented a particular inconvenience to research efforts in this laboratory, an attempt was made to develop an effective Harlow-style surrogate. Two surrogates were tested, a flashing 7-W colored light bulb and a modified red tennis ball.

\section{METHOD}

\section{Subjects}

Subjects were 108 White Leghorn chickens obtained from a local hatchery and hatched into Number 2 brown paper bags. Isolates were placed in complete visual isolation for 8 days, with an 8 -day supply of Purina Chick Starter in 22 by 38 by $23 \mathrm{~cm}$ enclosures. Room temperature was $90^{\circ} \mathrm{F}$, with a 14-h photoperiod of artificial light. Fresh water was supplied daily through a hole in the top of the cage. A slit in the side of the cage allowed in the experimenter to observe ongoing behavior.

\section{Apparatus and Procedure}

In 20 of the cages, a red tennis ball with thumbtack eyes (white with $1 / 4$-in blue centers) and a small white bead nose was suspended from the cage roof so that it moved when touched. The ball was $9.5 \mathrm{~cm}$ above the floor. A flashing colored light (eight yellow, eight red, and nine blue) was attached to the upper left-hand corner of 25 of the cages. No modifications were made on another 37 cages. Twenty-six chicks were placed into a standard brooders with screening to prevent outside stimulation. Assignment to cages was random.

Chicks were observed daily between 2:00 and 4:00 p.m. The ongoing behavior was recorded, and dead chicks were removed from the cage. One cage was left empty, with a level cup of food and water in it to compare for differences between shrinkage and evaporation effects and the appearance that food or water has been consumed from a cup. 
Table 1

Number of Deaths Occurring Between the 4th and 7th Days in White Leghorn Chicks

\begin{tabular}{lrccc}
\hline & \multicolumn{3}{c}{ Surrogate } & \\
\cline { 2 - 4 } & Ball & Light & None & Group \\
\hline Number of chicks & 20 & 25 & 37 & 26 \\
Number of deaths & 5 & 18 & 28 & 3 \\
\hline
\end{tabular}

Table 2

Analysis of Z Differences in Death Rates Between the 4th and 7th Days After Hatching for Chicks Reared in Different Social Conditions

\begin{tabular}{lccc}
\hline & \multicolumn{3}{c}{ Surrogate } \\
\cline { 2 - 4 } $\begin{array}{l}\text { Rearing } \\
\text { Conditions }\end{array}$ & $\begin{array}{c}\text { Light } \\
\text { Reared }\end{array}$ & $\begin{array}{c}\text { Isolate } \\
\text { Reared }\end{array}$ & $\begin{array}{l}\text { Group } \\
\text { Reared }\end{array}$ \\
\hline Ball Reared & $3.13^{*}$ & $3.64^{*}$ & 1.18 \\
Light Reared & & & $4.28^{*}$ \\
Isolate Reared & & .36 & $4.92^{*}$ \\
\hline
\end{tabular}

${ }^{*} p<.01(n=20)$.

Note. $\hat{p}=\frac{y_{1}+y_{2}}{n_{1}+n_{2}} ; Z=\frac{\hat{p}_{1}-\hat{p}_{2}}{\hat{p} \hat{q}\left(\frac{1}{n_{1}}+\frac{1}{n_{2}}\right)}$

\section{RESULTS}

An analysis of $\mathrm{Z}$ differences (Mendenhall \& Ramey, 1973) on the data showed that the death rate did not differ significantly between group-reared chicks and chicks reared with red tennis balls, nor were there significant differences in death rates between isolate chicks and chicks reared with a flashing light surrogate. Groupreared and ball-reared chicks had a significantly lower death rate than did isolates and light-reared chicks. All chicks were observed to be eating or drinking on at least one occasion. Since chicks removed more food from the cups than they ate (scratching, jumping onto the foodcup, and roosting on the foodcup were observed to cause spillage), it was not possible to accurately assess any differences between shrinkage control cups and cage cups. Table 1 shows the actual death rate and Table 2 shows the significant differences between death rates.

\section{DISCUSSION}

Clearly, the flashing light surrogate was ineffective as a surrogate for chickens, while a red tennis ball made a highly effective surrogate. This suggests Harlow's work is more applicable to lower species than had previously been considered. Tactile stimulation, apparently, is thus more important for normal development than visual stimulation or food, for chicks as well as chimps. This is interesting in view of the Bateson and Reese (1968) work, in which ducks deprived of food, water, and contact with an imprinting object initially ignored food and water, ate and drank for $7 \mathrm{~min}$, and spent the rest of the hour approaching the imprinting stimulus. Isolate chicks were never able to make contact with the light. It seems that perhaps the need for making physical contact with the mother takes priority over the need for food and water. The mother hen is not needed to provide nutrients after birth. The chick lives for 3 days on the yolk of the egg, and all of the chicks in this study had been observed eating or drinking. However, since it was not ascertained how much food any given chick consumed, it would be possible that isolates devoted their energies to seeking contact with an imprinting stimulus to the detriment of maintaining eating behavior.

\section{REFERENCES}

Bateson. R.. \& Reese. E. P. Imprinting. Cambridge: AppletonCentury-Crofts, 1968. (Film)

Harlow, H.. \& Griffin, G. Induced mental and social deficits in rhesus monkeys. In S. F. Osler \& R. E. Cooke (Eds.), The biosocial basis for mental retardation. Baltimore: Johns Hopkins Press, 1965. Pp. 87-106.

Heron. W. The pathology of horedom. Scientific American. 1957. 196. 52-56.

HESS, E. H. "Imprinting" in animals. Scientific American, 1958. 198. 81-86.

Mendenhall. W.. \& Ramey, M. Stutistics for psychology. North Scituate. Mass: Duxberry, 1973. Pp. 169-171.

Osamu. F.. \& MasataKa. H. Effects of early rearing conditions and age upon open field behavior in chicks. Annual of Animal Psychology. 1971. 21, 31-42. (Abstract)

RATNER. S. C. Comparisons between behaviour development of normal and isolated domestic fowl. Animal Behaviour, 1965. 8. 497-503.

REESE, N. C. The effects of social experience on duration of tonic immobility ("animal hypnosis") in White Leghorn chickens. Unpublished doctoral dissertation, University of Southern Mississippi. 1976.

SALZEN. E. A. Imprinting and the immobility reactions of domestic fowl. Animal Behavior, 1963, 11, 66-71.

(Received for publication March 21, 1976.) 